\title{
Million Organisms
}

National Cancer Institute

\section{Source}

National Cancer Institute. Million Organisms. NCI Thesaurus. Code C71188.

A unit of measure of quantity of organisms expressed in millions. 